NBER WORKING PAPER SERIES

\title{
EMPIRICAL ESTIMATES FOR ENVIRONMENTAL POLICY MAKING IN A SECOND-BEST SETTING
}

\author{
Sarah E. West \\ Roberton C. Williams III \\ Working Paper 10330 \\ http://www.nber.org/papers/w10330
NATIONAL BUREAU OF ECONOMIC RESEARCH 1050 Massachusetts Avenue Cambridge, MA 02138
February 2004

For their helpful comments and suggestions, we thank Don Fullerton, Eban Goodstein, Larry Goulder, Michael Greenstone, Dan Hamermesh, Shulamit Kahn, Gib Metcalf, Ian Parry, Raymond Robertson, Dan Slesnick, Steve Trejo, Frank Wolak, Ann Wolverton, Pete Wilcoxen, and seminar participants at the Brookings Institution, the NBER Environmental Economics Working Group, the Universities of California (Berkeley), Maryland, Minnesota, Texas, and Virginia, Syracuse University, the Southern Economics Association, and the U.S. Environmental Protection Agency. For their excellent research assistance, we thank Chris Lyddy, Trey Miller, and Jim Sallee. The views expressed herein are those of the authors and not necessarily those of the National Bureau of Economic Research.

(C)2004 by Sarah E. West and Roberton C. Williams III. All rights reserved. Short sections of text, not to exceed two paragraphs, may be quoted without explicit permission provided that full credit, including (C) notice, is given to the source. 
Empirical Estimates for Environmental Policy Making in a Second-Best Setting Sarah E. West and Roberton C. Williams III

NBER Working Paper No. 10330

February 2004

JEL No. H21, H23, Q5

\section{ABSTRACT}

This study estimates parameters necessary to calculate the optimal second-best gasoline tax, most notably the cross-price elasticity between gasoline and leisure. Prior work indicates that in a secondbest setting with distortionary income taxes, both the cost of environmental regulation and the optimal environmental tax rate depend crucially on the cross-price elasticity between a polluting good and leisure. However, no prior study on second-best environmental regulation has estimated this elasticity. Using household data, we find that gasoline is a relative complement to leisure, and thus that the optimal gasoline tax is significantly higher than marginal damages - the opposite of the result suggested by the prior literature. Following this approach to estimate cross-price elasticities with leisure for other major polluting goods could strongly influence estimates of optimal environmental taxes.

Sarah E. West

Department of Economics

Macalester College

1600 Grand Avenue

St. Paul, MN 55105

wests@macalester.edu

Roberton C. Williams III

Department of Economics

University of Texas at Austin

Austin, TX 78712

and NBER

rwilliam@eco.utexas.edu 


\section{Introduction}

Growing concern about global warming and continuing struggles with local pollution and congestion have led to increased attention to regulations designed to correct these externalities. Economists have played an important role in determining the optimal design of these regulations. Pigou (1938) showed that pollution taxes should be set equal to marginal damage-the level that fully internalizes an externality. But the presence of pre-existing distortionary taxes changes this conclusion. Tullock (1967) first suggested that pollution taxes have an additional benefit besides improving the environment: the revenue from pollution taxes can replace revenue from preexisting distortionary taxes, thus reducing the deadweight loss from those taxes. This has since been termed the revenue-recycling effect. Subsequent work pointed out the tax-interaction effect, which arises when the pollution tax affects the equilibrium quantity of another taxed good, such as labor. ${ }^{1}$ A tax on the average consumption good leads to a fall in labor supply, because it lowers the real wage. In an economy with a pre-existing income tax, the marginal social benefit of labor exceeds its marginal social cost, and thus that fall in labor supply produces a welfare loss. The more substitutable the polluting good is for leisure, the larger the fall in labor supply, and thus the larger the loss. However, if the polluting good is a complement to leisure, then the pollution tax will increase labor supply, and this effect will actually yield a welfare gain.

The tax-interaction effect thus depends crucially on the cross-price elasticity between leisure and the polluting good, as does the optimal pollution tax rate. But, while prior analytical work allows this elasticity to take on any value, it has never been estimated; indeed, the extensive literature on second-best environmental regulation is almost exclusively theoretical and numerical, with virtually no empirical work. ${ }^{2}$ Thus, to calculate the tax-interaction effect for a particular

\footnotetext{
${ }^{1}$ This literature is far too extensive to provide a comprehensive summary here, but important papers include Sandmo (1975), Bovenberg and De Mooij (1994), Bovenberg and van der Ploeg (1994), Parry (1995), Goulder (1995), Bovenberg and Goulder (1996 and 1997), Goulder et al. (1999), Parry et al. (1999), and Fullerton and Metcalf (2001). These general-equilibrium effects are also important in a variety of non-environmental contexts. For examples, see Browning (1997) on the welfare cost of monopoly, Goulder and Williams (2003) on the excess burden of commodity taxes, Parry (1999) on agricultural policy, and Williams (1999) on trade policy.

${ }^{2}$ An exception is Jorgenson and Wilcoxen (1993), which uses empirical estimates to parameterize a computable general equilibrium model that is then used to study the costs of reducing carbon emissions. However, that paper assumed a separable utility function-which, as discussed below, implies that the cross-price elasticity with leisure is determined by the expenditure elasticity for the polluting good.
} 
policy, prior studies have needed to impose strong assumptions on the form of the utility function. Most assume that the utility function is homothetic and is weakly separable between leisure and consumption, implying that all goods are average leisure substitutes. In this case, the tax-interaction effect yields a welfare loss that exceeds the gain from revenue recycling, and thus the optimal pollution tax is less than marginal damage. ${ }^{3}$

These assumptions greatly simplify the analysis, but are highly unlikely to hold in practice; empirical studies that estimate the joint demand for goods and leisure decisively reject separability. ${ }^{4}$ This issue is not unique to environmental taxes: the effect of this cross-elasticity on the optimal tax is the same for a non-polluting good. But even for this broader class of goods, there are very few empirical studies that estimate optimal taxes-and, to our knowledge, none of those studies use micro data.

This paper estimates the cross-price elasticity between gasoline and leisure and uses that estimate to calculate the optimal second-best gasoline tax. We use data from the 1996 through 1998 Consumer Expenditure Surveys, merged with data from the American Chambers of Commerce Researchers' Association (ACCRA) cost of living index and the National Bureau of Economic Research's (NBER) TAXSIM model. This gives us detailed household-level data on labor supply, taxes, and prices and quantities consumed of gasoline and other goods.

Most commonly used functional forms impose separability, homotheticity, or both; the linear expenditure system (LES), for example, imposes additive separability, while a constant elasticity of substitution (CES) utility function is both separable and homothetic. We resolve this issue by using the Almost Ideal Demand System (AIDS) derived by Deaton and Muellbauer (1980). The AIDS gives a first-order approximation to any demand system, satisfies the axioms

\footnotetext{
${ }^{3}$ A few studies (e.g., Parry and Small, 2002 and Ballard, Goddeeris, and Kim, 2000) relax the assumption of homotheticity, but maintain separability, which implies that the cross-price elasticity is determined by the expenditure elasticity for the polluting good; luxuries are relative leisure substitutes (implying a lower optimal tax), while necessities are relative leisure substitutes (implying a higher optimal tax).

${ }^{4}$ Separability has been tested and rejected in many studies; see, for example, Abbott and Ashenfelter (1976), Barnett (1979), Blundell and Walker (1982), and Browning and Meghir (1991). But no prior study offers estimates of the cross-price elasticity between leisure and a polluting good. The closest is Diewert and Lawrence (1996), which uses macro-level data from New Zealand to estimate the cross-price elasticity between motor vehicles and leisure, but does not consider gasoline or miles driven.
} 
of choice, is simple to estimate, and does not impose either separability or homotheticity.

We find that the optimal second-best gasoline tax is roughly $35 \%$ above marginal external damage. In contrast, prior work suggests that second-best optimal pollution taxes are typically less than marginal external damage. The difference arises because we find that gasoline is more complementary to leisure than is the average good, which leads to a substantially higher optimal tax rate. One possible explanation for this result is that driving is a relatively time-intensive good, and time-intensive goods tend to be leisure complements, as suggested by Becker (1965). Another possible explanation is that the demand for leisure driving is much more elastic than the demand for commuting. In either case, our results suggest that the widely used assumptions of separability and homotheticity are not merely convenient simplifications, but can substantially affect policy conclusions. Perhaps more importantly, we show that these effects can be estimated, and provide a theoretical and empirical framework for doing so.

The next section of this paper develops a simple theoretical model and derives an expression for the optimal second-best environmental tax. Subsequent sections describe the empirical model, data, estimation results, and the implied optimal environmental tax. The final section presents conclusions and suggests directions for future research.

\section{A Theoretical Model}

This section presents a simple theoretical model and uses it to derive an expression for the optimal second-best environmental tax. This model is similar to those used in the prior literature, but, unlike most earlier work, does not assume that leisure is separable, that the utility function is homothetic, or that the polluting good is an average substitute for leisure. It also differs from prior models in that it allows for multiple households (and the possibility of multiple individuals in a household), rather than a representative agent. ${ }^{5}$

\footnotetext{
${ }^{5}$ Recent papers that use a similar model, but assume homotheticity and separability in deriving optimal taxes include Goulder et al. (1999), Parry et al. (1999), and Williams (2001). Parry and Small (2002) and Ballard et al. (2000) relax the assumption of homotheticity, but maintain separability. Kim (2002) provides a theoretical model that derives an expression for the optimal pollution tax without imposing separability or homotheticity, but does not include any empirical estimates using that expression. All of these papers assume a representative agent. As is briefly discussed in the next section, the aggregate demands in our system do not equal the demand of a representative household. Thus, we need to allow for multiple households in this theoretical model. While this model could also be used to study distributional effects, we do not consider that issue in this paper.
} 
Each household in the economy consumes a dirty consumption good $(D)$, a clean good $(C)$, and a government-provided public good $(G)$. The utility function for household $h$ is

$$
U^{h}\left(\mathbf{l}^{\mathbf{h}}, C^{h}, D^{h}, G\right)-\phi^{h}(D),
$$

where $U$ is continuous and quasi-concave and the function $\phi^{h}$ represents the disutility from an externality associated with the economy-wide total consumption of the dirty good. ${ }^{6}$ The elements $l^{h i}$ of the vector $\mathbf{l}^{\mathrm{h}}$ represent hours of leisure for each of the adults in the household. The time constraint for individual $i$ is

$$
\bar{L}=L^{h i}+l^{h i},
$$

where $\bar{L}$ is the time endowment and $L^{h i}$ is hours worked. The household budget constraint is

$$
p_{C}^{h} C^{h}+p_{D}^{h} D^{h}=Y^{h} \equiv I^{h}+\sum_{i} w^{h i} L^{h i}
$$

where $w$ is the after-tax wage, $I$ is after-tax non-labor income, and $Y^{h}$ is total after-tax income, which equals total expenditure. The consumer price of the dirty good $\left(p_{D}\right)$ is given by

$$
p_{D}^{h}=\bar{p}_{D}^{h}+\tau_{D},
$$

where $\bar{p}_{D}$ is the producer price and $\tau_{D}$ is a unit tax on the dirty good. The clean good is untaxed, and thus its producer price $\left(\bar{p}_{C}\right)$ and consumer price $\left(p_{C}\right)$ are equal. ${ }^{7}$ The after-tax wage is

$$
w^{h i}=\bar{w}^{h i}-\tau_{L}^{h i}
$$

where $\bar{w}$ is the pre-tax wage and $\tau_{L}$ is the marginal tax per unit of labor. After-tax non-labor income is given by

$$
I^{h}=\bar{I}^{h}-T^{h},
$$

where $\bar{I}$ is pre-tax non-labor income, and $T$ is a lump-sum tax or transfer. ${ }^{8}$

\footnotetext{
${ }^{6}$ We assume that the damage from the externality appears only as an additively separable term in utility. If damages were to enter in some other form, that could also affect labor supply and thus generate a second-best welfare effect. See Bovenberg and van der Ploeg (1994), Espinosa and Smith (2001), and Williams (2002 and 2003) for further discussion on this point. The present paper focuses on whether the polluting good is separable in utility, and thus ignores the question of whether damages are separable.

${ }^{7}$ Assuming that the clean good is untaxed leads to no loss of generality, because any tax system that taxes the clean good can be renormalized as a system with a higher income tax and no clean good tax (see, for example, Fullerton 1997). Williams (2001) shows that this renormalization does not affect the ratio of the optimal environmental tax to marginal damages.

${ }^{8}$ Note that $\tau_{L}$ and $T$ could represent a linear tax system or a (household-specific) local linear approximation to a nonlinear tax system.
} 
Each of the three goods is produced under perfect competition with constant returns to scale. We assume that non-labor income is derived from ownership of a fixed factor that is a perfect substitute for labor. ${ }^{9}$ These assumptions imply that the pre-tax wage and all producer prices are exogenously fixed and that the aggregate production constraint is

$$
\sum_{h}\left(\bar{I}^{h}+\sum_{i} \bar{w}^{h i} L^{h i}\right)=\bar{p}_{G} G+\sum_{h}\left[\bar{p}_{C}^{h} C^{h}+\bar{p}_{D}^{h} D^{h}\right],
$$

where $\bar{p}_{G}$ is the producer price of the public good. The government's budget constraint is

$$
\sum_{h}\left[\tau_{D}^{h} D^{h}+\sum_{i} \tau_{L}^{h i} L^{h i}+T^{h}\right]=\bar{p}_{G} G .
$$

The level of the public good is assumed to be fixed, with any change in revenue from the dirty good tax offset by adjusting $\tau_{L}$ and $T$, following

$$
\tau_{L}^{h i}=\hat{\tau}_{L}^{h i}+\tau_{Y}\left(\bar{w}^{h i}-\hat{\tau}_{L}^{h i}\right) \text { and } \mathrm{T}^{h}=\hat{T}^{h}+\tau_{Y}\left(\bar{I}^{h}-\hat{T}^{h}\right)
$$

where $\hat{\tau}_{L}^{h i}$ and $\hat{T}^{h}$ are constant, and $\tau_{Y}$ adjusts to hold government revenue constant as $\tau_{D}$ varies. Equation (9) implies that the reduction in household $h$ 's taxes from a decrease in $\tau_{Y}$ will be proportional to $Y^{h}$. This could represent adjusting a broad-based consumption tax, renormalized as an income tax, or could represent an income tax cut that is proportional to after-tax income. ${ }^{10}$

Each household maximizes utility (1) subject to its time constraint (2) and budget constraint (3), taking as given prices, tax rates, the level of the public good, and the level of pollution. This yields the first-order conditions

$$
\partial U^{h} / \partial C^{h}=p_{C}^{h} \lambda^{h} ; \partial U^{h} / \partial D^{h}=p_{D}^{h} \lambda^{h} ; \partial U^{h} / \partial l^{h i}=w^{h i} \lambda^{h},
$$

where $\lambda^{h}$ is the marginal utility of after-tax income. Together with the constraints given

\footnotetext{
${ }^{9}$ This assumption is clearly unrealistic, but it provides a simple way to introduce non-labor income into the model. For a similar model in which the fixed factor is not a perfect substitute for labor, see Williams (2002). Bovenberg and Goulder (1996) provide a model with non-labor income derived from capital, but it is much more complex than the model used here, and therefore cannot be solved analytically.

${ }^{10}$ We choose this approach for adjusting the income tax because it implies that raising the dirty good tax and lowering the income tax will not shift the tax burden from labor to non-labor income or vice-versa. In this model, a tax on non-labor income is nondistortionary, because we represent non-labor income as lump-sum. But in the real world, taxes on non-labor income are distortionary, and thus we do not want the model's results to be driven by the effect of shifting the tax burden onto or off of non-labor income. The results would be similar if the added revenue were used to purchase more of the public good, as long as the level of the public good is close to the optimum.
} 
previously, these implicitly define the (uncompensated) demand functions

$$
C^{h}\left(p_{C}^{h}, p_{D}^{h}, \mathbf{w}^{h}, I^{h}\right) ; D^{h}\left(p_{C}^{h}, p_{D}^{h}, \mathbf{w}^{h}, I^{h}\right) ; l^{h i}\left(p_{C}^{h}, p_{D}^{h}, \mathbf{w}^{h}, I^{h}\right) .
$$

To derive an expression for the aggregate change in utility from a change in the tax on the dirty good, we take the total derivative of utility (1) with respect to $\tau_{D}$, sum over households, substitute in the first-order conditions (10), subtract the total derivatives with respect to $\tau_{D}$ of the time constraint (2) and aggregate production constraint (7), and rearrange terms. This gives

$$
\sum_{h} \frac{1}{\lambda^{h}} \frac{d U^{h}}{d \tau_{D}}=\sum_{h}\left[\left(\tau_{D}-\tau_{P}\right) \frac{d D^{h}}{d \tau_{D}}-\sum_{i} \tau_{L}^{h i} \frac{d l^{h i}}{d \tau_{D}}\right],
$$

where $\tau_{P}$ is the Pigouvian tax, equal to the dollar value of marginal external damage per unit of $D$

$$
\tau_{P}=\sum_{h} \frac{1}{\lambda^{h}} \frac{\partial \phi^{h}}{\partial D}
$$

Expression (12) equals the change in deadweight loss in the two distorted markets: the distortion in the dirty good market $\left(\tau_{D}-\tau_{P}\right)$ times the change in dirty good consumption, plus the distortion in the labor market $\left(\tau_{L}\right)$ times the change in labor supply. Note that this is a pure efficiency measure; distributional issues, while important, are beyond the scope of this paper.

The total derivatives in (12) include not only the effect of the increase in the dirty good tax, but also the effect of the resulting income tax cut. This makes little difference for the dirty good, where the effect of the income tax change will be tiny relative to the effect of the dirty good tax, but will be much more important for labor supply. Thus, it is useful to rewrite the term for the labor market in (12) in terms of $\partial l / \partial p_{D}$ rather than $d l / d p_{D}$. To do this, we first define $\eta$, which is the marginal cost of public funds (MCPF). As shown in Appendix 1, $\eta$ is given by

$$
\eta=\sum_{h} Y^{h} / \sum_{h}\left[Y^{h}+\sum_{i} \tau_{L}^{h i}\left(\frac{\partial l^{h i}}{\partial I^{h}} I^{h}+\sum_{j} \frac{\partial l^{h i}}{\partial w^{h j}} w^{h j}\right)\right] .
$$

This is the marginal cost to households of raising government revenue via the income tax; thus, it is the ratio of the loss to households to the revenue raised for a marginal increase in this tax. ${ }^{11}$

\footnotetext{
${ }^{11}$ This definition of the MCPF is "non-environmental" in that it omits the effects of changes in environmental quality and changes in revenue from the environmental tax resulting from a change in the income tax. This expression for the MCPF and those typically used in the prior literature differ slightly because of differences in model assumptions. They are equivalent for the special case of this model that matches the typical assumptions in the prior literature: only one household, only one individual in that household, and no non-labor income.
} 
As shown in Appendix 1, the last term in (12) can now be rewritten as

$$
-\sum_{i} \tau_{L}^{h i} \frac{d l^{h i}}{d \tau_{D}}=\sum_{h}\left[(\eta-1)\left(D^{h}+\tau_{D} \frac{d D^{h}}{d \tau_{D}}\right)-\eta \sum_{i} \tau_{L}^{h i} \frac{\partial l^{h i}}{\partial p_{D}^{h}}\right] .
$$

To obtain an expression for the optimum tax on the dirty good, set (12) equal to zero, substitute in (15), and solve. This gives

$$
\tau_{D}^{*}=\frac{\tau_{P}}{\eta}+\sum_{h}\left[\sum_{i} \tau_{L}^{h i} \frac{\partial l^{h i}}{\partial p_{D}^{h}}-\frac{\eta-1}{\eta} D^{h}\right] / \sum_{h} \frac{d D^{h}}{d \tau_{D}} .
$$

The first term in this expression is the traditional Pigouvian tax divided by the marginal cost of public funds. This is the optimal tax when the dirty good is an average substitute for leisure. The second term shows the influence of the cross-price elasticity between the dirty good and leisure. When the dirty good is a stronger substitute for leisure than is the average good, this term is negative and thus decreases the optimal tax on the polluting good. If the dirty good is a weaker leisure substitute than the average good or is a complement to leisure, this term is positive and thus increases the optimal tax.

The prior literature typically assumes that utility is homothetic and that leisure is separable. This greatly simplifies the analysis, because it implies that the two terms in square brackets in (16) cancel, and therefore that the optimal tax is just $\tau_{P} / \eta$. Thus, these assumptions eliminate the need to estimate the cross-price elasticity between the dirty good and leisure.

Parry and Small (2002) and Ballard et al. (2000) relax the assumption of homotheticity, but still assume that leisure is separable in utility. This assumption allows the derivative of leisure demand with respect to the price of the dirty good to be expressed as

$$
\frac{\partial l^{h i}}{\partial p_{D}^{h}}=-D^{h}\left[\frac{\partial l^{h i}}{\partial I^{h}}+\varepsilon_{D X}^{h} \sum_{j} \frac{w^{h j}}{Y^{h}}\left(\frac{\partial l^{h i}}{\partial w^{h j}}-\frac{\partial l^{h i}}{\partial I^{h}} L^{h j}\right)\right],
$$

where $\varepsilon_{D X}$ is the expenditure elasticity of demand for gasoline. Under this assumption, a luxury must be a relative substitute for leisure, while a necessity must be a relative complement to leisure. Thus, this assumption also makes it possible to calculate the optimal pollution tax without directly estimating the cross-price elasticity between the dirty good and leisure. 


\section{An Empirical Model}

The optimal tax on the dirty good in (16) depends on several own-price and cross-price derivatives of demand. In this section, we first specify the demand system that we use to estimate these derivatives. Then we describe the data, variable derivation, and summary statistics. Finally, we discuss the estimation technique and system estimation results.

\section{A. Specification of the Demand System}

We use an Almost Ideal Demand System (AIDS), first derived in Deaton and Muellbauer (1980), defined over gasoline (the dirty good), leisure, and a composite of all other goods (the clean good). The advantages of the AIDS are well-known: it provides a first-order approximation to any demand system, satisfies the axioms of choice, and does not assume that the utility function is separable or homothetic.

In their budget share form, the AIDS demand equations for gasoline, leisure, and a composite of all other goods for household $h$ are:

$$
s_{j}^{h}=\alpha_{j}^{h}+\sum_{k} \gamma_{j k} \log p_{k}^{h}+\beta_{j} \log \left(y^{h} / P^{h}\right) \quad j, k=\text { gasoline, leisure, other goods; } h=1, \ldots, H
$$

where $\alpha, \beta$, and $\gamma$ are parameters to be estimated, and $y^{h}$ is full income, or total expenditures on gasoline, leisure, and other goods. ${ }^{12} P^{h}$ is the price index defined by:

$$
\log P^{h}=\alpha_{0}+\sum_{j} \alpha_{j}^{h} \log p_{j}^{h}+\frac{1}{2} \sum_{k} \sum_{j} \gamma_{j k} \log p_{j}^{h} \log p_{k}^{h} .
$$

Demand theory imposes several restrictions on the parameters of the model, including:

(20a) $\quad \sum_{j} \alpha_{j}^{h}=1$

$$
\text { (20b) } \sum_{j} \gamma_{j k}=0
$$$$
\text { (20c) } \sum_{j} \beta_{j}=0
$$$$
\text { (20d) } \gamma_{j k}=\gamma_{k j} \text {. }
$$

Under these restrictions, (18) represents a system of demand functions that add up to full income, are homogeneous of degree zero in prices and full income, and satisfy Slutsky symmetry. Use of the price index in (19) requires estimation of a nonlinear system of equations. To simplify estimation, Deaton and Muellbauer (1980) suggests a linear approximation to (19):

${ }_{12}$ Please note the slight change in notation. The theory model assigned letters $D, l$, and $C$ to the goods for consistency with the prior second-best literature. For compactness, this section uses subscript $j$ to index goods. Also note that full income $\left(y^{h}\right)$ as defined here differs from income $\left(Y^{h}\right)$ as defined in the theory model, in that $y^{h}$ includes the value of leisure consumed, while $Y^{h}$ does not. 


$$
\log P^{h} \cong \sum_{j} s_{j}^{h} \log p_{j}^{h}
$$

This price index, however, is not invariant to changes in units of measurement (see Moschini 1995). We therefore normalize prices to obtain the unit-invariant price index

$$
\log P^{h} \cong \sum_{j} s_{j}^{h} \log \left(p_{j}^{h} / \bar{p}_{j}\right)
$$

where $\bar{p}_{j}$ is the mean price over all households. ${ }^{13}$

\section{B. Data, Variable Derivation, and Summary Statistics}

The 1996 through 1998 Consumer Expenditure Surveys are the main components of our data. The CEX Family Interview files include the amount spent by each household on gasoline, total expenditures, and a wide variety of household income measures, all for the three months prior to the CEX interview. For each household member, the Member Files include usual weekly work hours, occupation, the gross amount of last pay, the duration of the last pay period, and a variety of member income measures. The CEX is a rotating panel survey. Each quarter, 20 percent of the sample is rotated out and replaced by new consumer units. We pool observations for households across quarters.

We estimate two demand systems: one for one-adult households and the other for twoadult households with one adult male and one adult female (where an adult is at least 18 years of age). ${ }^{14}$ Each adult's leisure is treated as a separate good. Thus, the two-adult demand system includes four goods: gasoline, male leisure, female leisure, and a composite of all other goods. The twelve quarters in the 1996 through 1998 Consumer Expenditure Surveys have 4659 one-adult households and 5047 two-adult households under 65 with complete records of the necessary variables. Each household appears in the data one to four times, giving a total of 9725 one-adult observations and 11034 two-adult observations. Females head 54 percent of the one-adult

\footnotetext{
${ }^{13}$ Note that the use of any linear approximation to the price index in (19) implies that the symmetry restriction (20d) is also an approximation.

${ }^{14}$ We exclude households with adults over the age of 65 . Less than 5 percent of those over 65 work, and thus nonlabor income is very important for this group. We do not realistically model capital income, as discussed in Section II. Thus, excluding those over 65 likely introduces much less error than would including this group.
} 
households. In one adult households, 78 percent of women and 83 percent of men work. In twoadult households, 71 percent of women and 88 percent of men work.

Full income $\left(y^{h}\right)$ equals the amount spent on gasoline, leisure, and all other goods. The CEX contains quarterly gasoline expenditure. Since it also contains hours worked per week, we divide quarterly gasoline expenditure by 13 to get weekly gas expenditure. To derive weekly leisure “expenditure," we need to specify each person's time endowment. The highest number of hours worked in the sample is 90 per week, so we set the weekly time endowment at 90 hours. We then subtract the number of hours worked per week from 90 to get weekly leisure hours. ${ }^{15}$ To obtain the price of leisure (the wage) we first calculate the wage net of tax using state and federal effective tax rates from the NBER's TAXSIM model. ${ }^{16}$ Since we do not observe wages for individuals who do not work, we follow Heckman (1979) to correct for selectivity bias. We explain this estimation in more detail in Appendix 2. We multiply the selectivity-corrected net wage by the number of hours of leisure per week to obtain weekly leisure expenditure.

To calculate weekly spending on other goods, we first convert the CEX's measure of quarterly total expenditures into weekly total expenditures. Then we subtract weekly gasoline expenditure from total weekly expenditures to obtain spending on all other goods.

For gas prices and the price of other goods, we use the ACCRA cost-of-living index. This index compiles prices of many separate goods as well as overall price levels for approximately 300 cities in the United States. It is most widely used to calculate differences in overall cost-ofliving across cities. It also lists for each quarter the average prices of regular, unleaded, nationalbrand gasoline. Since the CEX reports state of residence of each household, and not city, we average the city prices within each state to obtain a state gasoline price and price index for each

\footnotetext{
${ }^{15}$ Demand system estimates can be sensitive to the choice of time endowment. We therefore experimented with time endowments of 100 and 112 hours per week. In neither case do the results change significantly.

${ }^{16}$ Estimates of marginal and average tax rates should be reasonably accurate given the level of detail in the TAXSIM model, which incorporates state and federal tax brackets, the earned income tax credit, the child tax credit, deductibility of state income taxes, and other important features of the tax code. Some of these features, such as credit phase-outs, may cause the marginal tax rate to differ from the statutory marginal rate. Therefore, marginal tax rates are calculated based on a $\$ 1000$ increase in earned income. For more detail on the TAXSIM model, see Feenberg and Coutts (1993). These tax rate estimates, however, do not include sales taxes or Social Security payroll taxes, and thus will understate the true tax rate. Consequently, our results will tend to understate the importance of second-best effects.
} 
calendar quarter. Then we assign a gas price and a price index to each household based on state of residence and CEX quarter. For households whose CEX quarters overlap two quarters of price data, we use a weighted average of those two quarters. We use the ACCRA price index divided by 100 as our price of other goods. We calculate the price index $\left(P^{h}\right)$ using equation (22).

Table 1 lists summary statistics for the demand system estimation sample, working households that consume gasoline. Both one- and two-adult households spend about 2 percent of their income on gasoline. One-adult households spend a bit less than 50 percent of their total income on leisure and the remainder on other goods. Two-adult households spend about 55 percent of their income on leisure and the remainder on other goods. The average selectivitycorrected net wage is $\$ 8.31$ per hour in the one-adult sample, and $\$ 11.02$ per hour for men and $\$ 8.60$ per hour for women in the two-adult sample. ${ }^{17}$

\section{System Estimation and Results}

To incorporate the effect that household and individual specific characteristics have on demand, we add a vector of these characteristics, $c_{r}^{h}$, to the constant terms in (18) so that:

$$
\alpha_{j}^{h}=\zeta_{j 0}+\sum_{r} \zeta_{j r} c_{r}^{h}, \quad j=\text { gasoline, leisure, other goods }
$$

where $\zeta_{j 0}$ and the $\zeta_{j r}$ 's are parameters to be estimated.

Some households also have zero expenditure on gasoline. To correct for the selection bias that may arise, we first estimate a probit on the choice of whether to consume gasoline. From that probit, we obtain inverse Mills ratios $\left(R_{g}^{h}\right)$ for gasoline (see Appendix 2 for details on this estimation). Substituting equation (23) into equation (18) and adding $R_{g}^{h}$ and error term $e_{j}^{h}$ yield the following equations for estimation:

$$
s_{j}^{h}=\zeta_{j 0}+\sum_{r} \zeta_{j r} c_{r}^{h}+\sum_{k} \gamma_{j k} \log p_{k}^{h}+\beta_{j} \log \left(y^{h} / P^{h}\right)+\theta_{j} R_{g}^{h}+e_{j}^{h}
$$

We estimate the demand system defined by (24) using working households that consume gasoline, separately for one-adult and two-adult households. We impose the restrictions in (20a-

\footnotetext{
17 The wage distribution in our sample closely follows the distribution in the 1997 Current Population Survey.
} 
d) and drop the equation for other goods. Each system includes member and household characteristics that may affect gasoline or leisure shares: the members' age, age squared, race, sex (in one-adult estimation only), education, and number of children. ${ }^{18}$ In addition, a wide range of local factors could affect gasoline use or work behavior-everything from availability of public transportation to local urban design to cultural differences. Because many of these factors are unmeasurable, we include state fixed effects to account for them. Finally, because gasoline demand varies throughout the year, we include fixed effects for the month of the CEX interview.

Under this approach, the own-price gas demand elasticity is identified primarily based on differences across states in quarter-to-quarter gas price variation, because cross-state variation is picked up by the state fixed effects and month-to-month variation by the month fixed effects. The own-price and cross-price labor supply elasticities are identified primarily by cross-section variation in wages within each state. ${ }^{19}$ This requires the implicit assumption that unobserved household characteristics are not correlated both with wages and with gasoline consumption or hours worked.

Because some regressors may be endogenous, we use instrumental variables techniques. The net wage, for example, may be endogenous for two reasons. First, the gross wage is determined by dividing earnings by hours of work, and both variables may be measured with error. Thus, hours worked and wage rates may be correlated. Second, the marginal income tax rate depends on income. We therefore use the mean net wage by occupation by state, calculated separately for men and for women, to instrument for the net wage. ${ }^{20}$

The real income term $\ln \left(y^{h} / P^{h}\right)$ may also be endogenous, because it is a function of

\footnotetext{
${ }^{18}$ Note that the probits used to correct for selectivity bias include at least one variable not included in demand system estimation. West (2004) uses a similar data set to estimate the demand for vehicle miles traveled and finds that accounting for vehicle type results in less elastic demand. We do not account for vehicle type in this paper. The more inelastic is demand for gasoline, the farther the optimal tax will be from the standard second-best result.

${ }^{19}$ It might therefore seem that we estimate long run labor supply elasticities and short run gas demand elasticties. But since the coefficients in the demand system are estimated jointly, none of our elasticities is strictly short-run or long-run.

${ }^{20}$ Observations for workers in two occupation categories (farming, forestry, fishing, and groundskeeping is the first and the armed forces the second) are spread very thinly across states. For workers with these occupations, we instrument for net wage with the national mean net wages by occupation rather than the state level means.
} 
individual-specific shares that are also dependent variables. We instrument for this term, using a price index obtained by replacing the individual-specific shares in (22) with the sample mean shares. $^{21}$ Gasoline prices may also be endogenous. In the absence of a good instrument for statelevel gas prices, however, we do not control for this potential endogeneity. ${ }^{22}$

Since the equations in (24) are functions of the same explanatory variables, we expect error terms among the equations to be correlated. We therefore estimate the demand system using three-stage least squares (3SLS). This enables us to impose the cross-equation restrictions in equations (20a-d), use instrumental variables to obtain consistent estimates, and use generalized least squares to account for the error correlation structure across equations. ${ }^{23}$

Tables 2 and 3 present the system estimation results along with standard errors based on 1500 replications of a nonparametric bootstrap. Each bootstrap replication recomputes the Heckman-corrected wage and the inverse Mills ratios from the discrete choice of whether to consume gasoline, as well as the regression coefficients. Thus, the standard error estimates incorporate variation in the estimated selectivity-corrected wages and inverse Mills ratios. Because observations for the same household for multiple quarters are not independent, we cluster observations by household in generating each bootstrap sample.

In the one-adult sample, the gasoline share decreases with the wage rate. It is higher for blacks, males, and those with less education or more children. The leisure share decreases with the wage and the price of the other good, and increases with the price of gas. It is lower for blacks and those with less education or more children. The two-adult estimates generally mirror the oneadult estimates, though the magnitudes differ. The share of leisure (for either adult) increases with

\footnotetext{
${ }^{21} \mathrm{We}$ also estimate our system using the real income term calculated using this alternative index (keeping the wage instrument but with no price instrument), which does not noticeably affect any of the results. Using estimates from running the demand system with no instruments whatsoever also does not noticeably affect the results.

${ }^{22}$ Because we include state fixed effects, state-level gas tax rates are poor instruments for gas prices; in our sample, they explain only about 1 percent of the variation in gas prices.

${ }^{23}$ In principle, the full econometric model, including all discrete and continuous choices, might be estimated using maximum likelihood, but this would be difficult to implement. Since censoring occurs in both gasoline and leisure demand, and for either or both the male and female in two-adult households, we would need to evaluate multiple integrals in the likelihood function. Furthermore, such a procedure would probably be too computationally intensive to be practical, given that we need to bootstrap standard errors for our elasticity and optimal tax estimates.
} 
his or her wage and decreases with the wage of the other adult in the household.

Tables 4 and 5 present elasticities for the one-adult and two-adult samples, respectively, along with bias-corrected bootstrap confidence intervals. These elasticities are calculated separately for each household and then aggregated, rather than being calculated for a representative household. ${ }^{24}$ Compensated own-price gas and other good demand elasticities are negative, and compensated own-wage labor elasticities are positive. Gasoline own-price elasticity estimates are roughly -0.75 for one-adult households and -0.27 for two-adult households, which fall in the span of estimates reported in gas demand surveys. ${ }^{25}$

For one-adult households, the compensated and uncompensated labor supply elasticities are 0.35 and 0.04 , respectively. For two-adult households, compensated own-wage labor supply elasticities are 0.19 for men and 0.34 for women, while uncompensated elasticities are 0.06 and 0.24. These fall into the range reported in the survey by Fuchs et al. (1998). Compensated crosswage labor elasticities are insignificantly positive, while uncompensated elasticities are negative; men and women respond to increases in their partner's wage by working less.

The other important elasticity in equation (16) is the uncompensated cross-price elasticity of labor with respect to the price of gasoline. A positive value for this elasticity raises the optimal gas tax, because in this case an increase in the price of gasoline increases labor supply and generates a second-best welfare gain. A negative value reverses this effect, lowering the optimal tax. The prior literature has implicitly assumed a slightly negative value for this elasticity, as a result of assuming separability and homogeneity. In contrast, we find that this elasticity is positive for one-adult households and for both genders in two-adult households, though it is significant only for men in two-adult households (an elasticity of 0.013). This implies a higher optimal gas tax rate than has been suggested by prior work.

One possible explanation for this result is that a higher gas price leads to a reduction in

\footnotetext{
${ }^{24}$ In many cases, aggregate demand elasticities under the AIDS are equal to the elasticity for a representative household, but that property does not hold when some households are at a corner solution, as is the case here. Thus, it is necessary to aggregate individual household elasticities. Appendix 1 provides equations for the household demand elasticities in terms of the estimated parameters and for elasticity aggregation.

${ }^{25}$ See Dahl and Sterner (1991) or Espey (1996).
} 
leisure driving that is substantially greater than the reduction in work-related driving (primarily commuting). Parry and Small (2002) note that commuting makes up less than half of all vehicle miles traveled in the US, and it is reasonable to think that the demand for leisure driving would be more elastic than the demand for work-related driving. A more sophisticated argument is that driving is a relatively time-intensive activity (at the margin, once households have incurred the fixed cost of buying a car). Becker's (1965) model of time use suggests that time-intensive goods are complements to leisure (or, more precisely, to non-market time).

This result is sensitive to the inclusion of state fixed effects: dropping the state fixed effects switches the sign on the elasticity of labor supply with respect to the gas price from positive (meaning gas and leisure are complements) to negative (gas and leisure are substitutes). This suggests that unobserved state-level variables are quite important. In contrast, dropping month fixed effects has little effect on the results.

\section{Optimal Tax Calculations}

This section calculates the optimal second-best gasoline tax rate and compares it to the rates implied by the two formulas from the prior literature: one that assumes separability and homotheticity, and one that assumes only separability.

Our data set provides values for most of the variables in the formulas for the optimal tax rate (16) and the marginal cost of public funds (14), while the estimates from the previous section allow us to calculate all of the necessary derivatives of demand. ${ }^{26}$ The only additional parameter value needed is the marginal external damage from gasoline. We take this value from Parry and Small (2002), who estimate marginal damages at 83 cents per gallon in year 2000 dollars, a figure that incorporates pollution, congestion and accident externalities. To make this number

\footnotetext{
${ }^{26} \mathrm{We}$ assume that the derivatives of demand at the optimum are the same as those present in the status quo (which are what we estimated). In addition, equation (16) depends on the total derivative of gasoline demand with respect to the gas tax. This derivative is neither strictly uncompensated (because the total derivative includes the effect of reducing the income tax) nor strictly compensated (because the income tax cut does not fully compensate for the increased gas tax). However, as long as the tax rates are relatively small, this total derivative will be very close to the compensated derivative, and thus we use that value. Finally, for consistency with the model in Section II, where the externality was associated exclusively with a final good, we assume that the tax is imposed only on consumer use of gasoline, not on gasoline used as an intermediate good. Parry and Small (2002) note that intermediate use of gasoline is only a very small share of the total, so this seems like a reasonable assumption.
} 
consistent with the rest of our data, we use the CPI to deflate it, yielding an estimate of 77 cents in 1997 dollars, which we assume remains constant as the gas tax rate changes.

Substituting the appropriate values into equation (14) yields estimates for the MCPF of 1.01 in the one-adult sample, 1.03 in the two-adult sample, and 1.02 in the full sample. These estimates are somewhat lower than the values for the MCPF used by the prior literature, for two reasons. First, our estimate of the uncompensated labor supply elasticity is slightly lower than the prior literature had assumed. Second, marginal tax rates in our data are somewhat lower than what the prior literature has assumed (at least partly because, as noted previously, our tax rate data include only income taxes, omitting sales taxes and payroll taxes). For comparison, Goulder et al. (1999) and Parry et al. (1999) assume an uncompensated labor supply elasticity of 0.15 and a tax rate of $40 \%$, which together imply an MCPF of 1.11 .

The now-standard formula from the prior literature, which assumes that utility is homothetic and separable, states that the optimal second-best tax is equal to marginal damages divided by the marginal cost of public funds $(\mathrm{MCPF})$. This would imply a gas tax of $\$ 0.76$ per gallon in the one-adult sample, $\$ 0.75$ in the two-adult sample, and $\$ 0.75$ for the full sample.

Relaxing the assumption of homotheticity but keeping separability gives a somewhat higher optimal tax, as in Parry and Small (2002). Substituting (17) and the appropriate parameter values into (16) yields an optimal tax of $\$ 0.87$ for the one-adult sample, $\$ 1.01$ for the two-adult sample, and $\$ 0.93$ for the full sample-all significantly above marginal damages. Because gasoline is a necessity, equation (17) implies that it is a relative leisure complement. Thus, increasing the gasoline tax decreases labor supply by less than an equivalent increase in the tax on other goods, implying a smaller loss from the tax interaction effect and a higher optimal tax rate.

Relaxing both separability and homotheticity gives the optimal tax formula from equation (16). When we substitute the appropriate parameter estimates into (16), we get a second-best optimal gasoline tax of $\$ 0.82$ in the one-adult sample, $\$ 1.30$ in the two-adult sample, and $\$ 1.04$ per gallon for the full sample. The difference between this rate and marginal damages is statistically significant at the $95 \%$ level for either the two-adult sample or the full sample, as is the difference between this rate and the optimal tax assuming both separability and 
homotheticity. The difference from the optimal tax assuming only separability is significant at the $90 \%$ level. Our estimates suggest that increasing the gasoline tax will actually increase labor supply, which implies that the tax-interaction effect will actually generate a welfare gain, rather than the loss suggested by the prior literature. Thus, the optimal tax rate is higher.

The difference between the optimal second-best tax and marginal external damage-a difference of 27 cents per gallon (35\% of marginal damages) for the full sample-is not enormous, but is quite important. And this difference has the opposite sign from what the prior literature has suggested. That literature has certainly noted the theoretical possibility that the optimal tax may exceed marginal damage, for exactly the reasons found here, but gave no clear indication of how likely such an outcome might be or of how large the difference would be.

Comparing the impact of including second-best effects with and without assuming separability and homotheticity demonstrates the importance of these assumptions. Given these point estimates, the difference caused by relaxing the assumptions of separability and homotheticity (a rise from $\$ 0.75$ to $\$ 1.04$ in the optimal tax) is more than ten times as large as the difference caused by incorporating second-best effects in the first place (\$0.77 to $\$ 0.75)$-the difference that has been the primary focus of the literature thus far.

Finally, we consider whether raising the gas tax would yield a "double dividend": that is, if it would produce a welfare gain even if marginal external damage were zero. Substituting a value of zero for $\tau_{P}$ in (16) yields an estimated optimal tax of $\$ 0.28$. This suggests the existence of a double dividend from raising the gas tax above zero, but not from raising it above the average rate in our sample (\$0.34). However, the $95 \%$ confidence interval for the optimal tax in this case runs from $\$ 0.11$ to $\$ 0.72$, so we cannot reject the hypothesis that raising the gas tax would yield a double dividend-or, to put it differently, that the optimal gas tax would exceed the current rate even if there were no externalities associated with gasoline use.

\section{Conclusions}

This paper estimates a complete consumer demand system without imposing separability or homotheticity, and applies those estimates together with a simple theoretical model to 
calculate the second-best optimal tax on gasoline. Contrary to the prior literature, which suggests that optimal environmental taxes are less than marginal external damage, we find that the optimal tax substantially exceeds marginal damage. The difference arises because gasoline is more complementary to leisure than is the average good, while typical assumptions in the prior literature imply that the polluting good is an average substitute for leisure.

This result has important implications both for policy and for future research. One obvious implication is that the efficiency gain from increasing the gas tax would be even larger than a first-best analysis would indicate. However, given the necessary simplifications in the model (most notably that it ignores capital), some caution should be exercised in drawing policy conclusions from this result. Perhaps more importantly, the practical relevance of any result on optimal gasoline taxes is limited by political constraints; the existing tax in the U.S. is far below what almost any economic analysis would indicate as the optimum.

Our result also has implications for the general problem of setting environmental taxes in a second-best world. Some readers may be tempted to use our results to support setting other environmental taxes at levels above marginal damages. This conclusion does not necessarily follow, given that other polluting goods are used for very different purposes than is gasoline. But our result does show that the case in which tax-interaction effects cause the optimal tax to exceed marginal damages is relevant in practice, not merely a theoretical possibility. This indicates far more uncertainty about the influence of second-best effects on environmental policy than prior work has suggested, and it shows that the widely used separability and homotheticity assumptions are not merely convenient simplifications; they can have large effects on the results.

Perhaps more importantly, we show that it is possible to estimate empirically the influence of these assumptions on the second-best optimal environmental tax, and we provide the necessary empirical and theoretical framework to do so. This approach can be fruitfully applied not only to other polluting goods, but also to non-polluting goods, to yield better estimates of optimal tax rates and of the deadweight losses from taxes on these goods. 


\section{References}

Abbott, Michael and Orley Ashenfelter, 1976. "Labour Supply, Commodity Demand and the Allocation of Time." Review of Economic Studies 43:389-411.

Ballard, Charles, John Goddeeris and Sang-Kyum Kim, 2000. "Non Homothetic Preferences and the Non-Environmental Effects of Environmental Taxes." Working Paper.

Barnett, William A., 1979. "The Joint Allocation of Leisure and Goods Expenditure.” Econometrica 47:539-563.

Becker, Gary, 1965. “A Theory of the Allocation of Time.” The Economic Journal 75:493-517.

Blundell, Richard and Ian Walker, 1982. "Modelling the Joint Determination of Household Labour Supplies and Commodity Demands.” The Economic Journal 92:351-364.

Bovenberg, A. Lans and Ruud A. de Mooij, 1994. "Environmental Levies and Distortionary Taxation." American Economic Review 85:1085-1089.

Bovenberg, A. Lans and Lawrence H. Goulder, 1996. "Optimal Environmental Taxation in the Presence of Other Taxes: General Equilibrium Analyses.” American Economic Review 96:985-1000.

Bovenberg, A. Lans and Lawrence H. Goulder, 1997. "Costs of Environmentally Motivated Taxes in the Presence of Other Taxes: General Equilibrium Analyses." National Tax Journal L(1):59-87.

Bovenberg, A. Lans and Frederick van der Ploeg, 1994. "Green policies and public finance in a small open economy." Scandinavian Journal of Economics 96:343-63.

Browning, Edgar, 1997. "A Neglected Welfare Cost of Monopoly-And Most Other Product Market Distortions.” Journal of Public Economics 66:127-144.

Browning, Martin and Costas Meghir, 1991. "The Effects of Male and Female Labor Supply on Commodity Demands.” Econometrica 59:925-951.

Dahl, Carol, and Thomas Sterner, 1991. "Analyzing Gasoline Demand Elasticities: A Survey." Energy Economics 13:203-210.

Deaton, Angus and John Muellbauer, 1980. "An Almost Ideal Demand System.” American Economic Review 70:312-326.

Diewert, W. Erwin, and Denis A. Lawrence, 1996. "The deadweight costs of taxation in New Zealand.” Canadian Journal of Economics 29:S659-S673. 
Espey, Molly, 1996. "Explaining the Variation in Elasticity Estimates of Gasoline Demand in the United States: A Meta-Analysis.” The Energy Journal 17:49-60.

Espinosa, J. Andres and V. Kerry Smith, 2001. "Environmental Levies with Non-Separable Damages.” working paper, North Carolina State University.

Feenberg, Daniel and Elisabeth Coutts, 1993. "An Introduction to the TAXSIM Model." Journal of Policy Analysis and Management 12:189-194.

Fuchs, Victor R., Alan B. Krueger and James M. Poterba, 1998. "Economists' Views about Parameters, Values and Policies: Survey Results in Labor and Public Economics." Journal of Economic Literature 36:1387-1425.

Fullerton, Don, 1997. "Environmental Levies and Distortionary Taxes: Comment." American Economic Review 87:245-251.

Fullerton, Don and Gilbert Metcalf, 2001. "Environmental Controls, Scarcity Rents, and PreExisting Distortions.” Journal of Public Economics 80:249-267.

Goulder, Lawrence, 1995. "Environmental Taxation and the Double Dividend: A Reader's Guide." International Tax and Public Finance 2:157-183.

Goulder, Lawrence H., Ian W. H. Parry, Roberton C. Williams III, and Dallas Burtraw, 1999. "The Cost-Effectiveness of Alternative Instruments for Environmental Protection in a Second-Best Setting." Journal of Public Economics, 72:329-360.

Goulder, Lawrence H. and Roberton C. Williams III, 2003. "The Substantial Bias from Ignoring General Equilibrium Effects in Estimating Excess Burden, and a Practical Solution." Journal of Political Economy 111:898-927.

Heckman, James, 1979. "Sample Selection Bias as Specification Error.” Econometrica 47:153161.

Heien, Dale and Cathy Wessels, 1990. "Demand System Estimation with Microdata: A Censored Regression Approach.” Journal of Business and Economic Statistics 8:365-371.

Jorgenson, Dale W. and Peter J. Wilcoxen, 1993. "Reducing U.S. Carbon Emissions: An Econometric General Equilibrium Assessment.” Resource and Energy Economics 15:7-26.

Kim, Seung-Rae, 2002. "Optimal Environmental Regulation in the Presence of Other Taxes: The Role of Non-separable Preferences and Technology." Contributions to Economic Analysis \& Policy: Vol. 1: No. 1, Article 4.

Moschini, Giancarlo, 1995. "Units of Measurement and the Stone Index in Demand System Estimation.” American Journal of Agricultural Economics 77:63-68. 
Parry, Ian, 1995. "Pollution Taxes and Revenue Recycling." Journal of Environmental Economics and Management 29:S64-S77.

Parry, Ian, 1999. “Agricultural Policies in the Presence of Distorting Taxes." American Journal of Agricultural Economics 81:212-230.

Parry, Ian, and Kenneth Small, 2002. "Does Britain or America Have the Right Gasoline Tax." working paper, Resources for the Future and University of California-Irvine.

Parry, Ian W. H., Roberton C. Williams III, and Lawrence H. Goulder, 1999. "When Can Carbon Abatement Policies Increase Welfare? The Fundamental Role of Distorted Factor Markets." Journal of Environmental Economics and Management, 37:52-84.

Pigou, A.C., 1938. The Economics of Welfare (4 ${ }^{\text {th }}$ ed.). London: Weidenfeld and Nicolson.

Sandmo, Agnar, 1975. "Optimal Taxation in the Presence of Externalities." Swedish Journal of Economics 77:86-98.

Shonkwiler, J. Scott and Steven T. Yen, 1999. "Two-Step Estimation of a Censored System of Equations." American Journal of Agricultural Economics 81:972-982.

Tullock, Gordon, 1967. “Excess Benefit.” Water Resources Research 3: 643-4.

West, Sarah, 2004. "Distributional Effects of Alternative Vehicle Pollution Control Policies." Journal of Public Economics 88:735-757.

Williams, Roberton C., III, 1999. "Revisiting the Cost of Protectionism: The Role of Tax Distortions in the Labor Market." Journal of International Economics, 47:429-447.

Williams, Roberton C., III, 2001. "Tax Normalizations, the Marginal Cost of Funds, and Optimal Environmental Taxes." Economics Letters, 71:137-142.

Williams, Roberton C., III, 2002. "Environmental Tax Interactions When Pollution Affects Health or Productivity." Journal of Environmental Economics and Management, 44:261270.

Williams, Roberton C., III, 2003. "Health Effects and Optimal Environmental Taxes." Journal of Public Economics, 87:323-335. 
Table I: Summary Statistics for Working Households with Non-zero Gas Consumption*

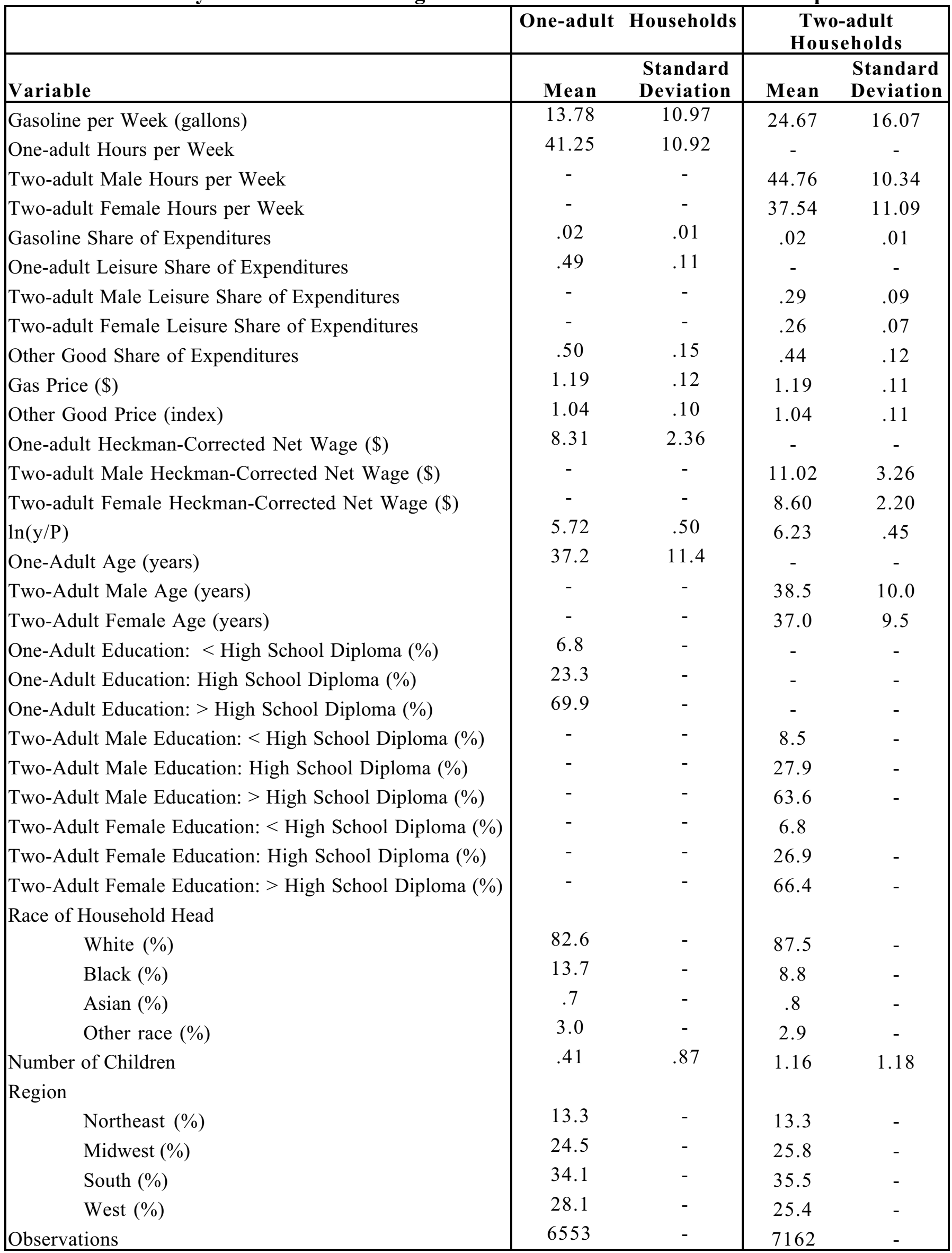

* Of the one-adult households $46 \%$ are headed by males while $54 \%$ are headed by females. 
Table 2: One-adult Household Demand System Estimation Results*

\begin{tabular}{|c|c|c|}
\hline $\ln ($ gas price) & $\begin{array}{c}\text { Gas Share } \\
0.0038 \\
(0.0026)\end{array}$ & $\begin{array}{c}\text { Leisure Share } \\
-0.0047 \\
(0.0017)\end{array}$ \\
\hline $\ln ($ other good price) & $\begin{array}{c}0.0009 \\
(0.0030)\end{array}$ & $\begin{array}{l}-0.1071 \\
(0.0163)\end{array}$ \\
\hline $\ln ($ net wage $)$ & $\begin{array}{l}-0.0047 \\
(0.0017)\end{array}$ & $\begin{array}{c}0.1119 \\
(0.0165)\end{array}$ \\
\hline $\ln (\mathrm{y} / \mathrm{P})$ & $\begin{array}{l}-0.0131 \\
(0.0008)\end{array}$ & $\begin{array}{l}-0.1829 \\
(0.0145)\end{array}$ \\
\hline Inverse Mills Ratio (gasoline) & $\begin{array}{l}-0.0150 \\
(0.0018)\end{array}$ & $\begin{array}{c}0.4710 \\
(0.0382)\end{array}$ \\
\hline Age & $\begin{array}{l}-0.0002 \\
(0.0002)\end{array}$ & $\begin{array}{c}0.0014 \\
(0.0027)\end{array}$ \\
\hline Age Squared & $\begin{array}{c}0.000002 \\
(0.000002)\end{array}$ & $\begin{array}{l}-0.000014 \\
(0.000034)\end{array}$ \\
\hline Black & $\begin{array}{c}0.0018 \\
(0.0007)\end{array}$ & $\begin{array}{l}-0.0824 \\
(0.0140)\end{array}$ \\
\hline Asian & $\begin{array}{l}-0.0010 \\
(0.0027)\end{array}$ & $\begin{array}{c}0.0306 \\
(0.0407)\end{array}$ \\
\hline Other Race & $\begin{array}{c}0.0003 \\
(0.0014)\end{array}$ & $\begin{array}{l}-0.0483 \\
(0.0241)\end{array}$ \\
\hline High School Degree & $\begin{array}{l}-0.0059 \\
(0.0014)\end{array}$ & $\begin{array}{c}0.1147 \\
(0.0201)\end{array}$ \\
\hline More than High School Degree & $\begin{array}{l}-0.0094 \\
(0.0016)\end{array}$ & $\begin{array}{c}0.1619 \\
(0.0222)\end{array}$ \\
\hline Female & $\begin{array}{l}-0.0041 \\
(0.0007)\end{array}$ & $\begin{array}{c}0.0099 \\
(0.0124)\end{array}$ \\
\hline Number of Children & $\begin{array}{c}0.0014 \\
(0.0003)\end{array}$ & $\begin{array}{l}-0.0158 \\
(0.0041)\end{array}$ \\
\hline Constant & $\begin{array}{c}0.1336 \\
(0.0075)\end{array}$ & $\begin{array}{c}1.2255 \\
(0.1229)\end{array}$ \\
\hline Number of Observations & 6553 & 6553 \\
\hline
\end{tabular}


Table 3: Two-adult Household Demand System Estimation Results*

\begin{tabular}{|c|c|c|c|}
\hline $\ln ($ gas price $)$ & $\begin{array}{c}\text { Gas Share } \\
0.0102 \\
(0.0018)\end{array}$ & $\begin{array}{c}\text { Male Leisure } \\
-0.0061 \\
(0.0010)\end{array}$ & $\begin{array}{c}\text { Female Leisure } \\
-0.0031 \\
(0.0009)\end{array}$ \\
\hline $\ln ($ other good price) & $\begin{array}{l}-0.0011 \\
(0.0020)\end{array}$ & $\begin{array}{l}-0.0604 \\
(0.0094)\end{array}$ & $\begin{array}{l}-0.0491 \\
(0.0075)\end{array}$ \\
\hline $\ln ($ male net wage) & $\begin{array}{l}-0.0061 \\
(0.0010)\end{array}$ & $\begin{array}{c}0.1383 \\
(0.0086)\end{array}$ & $\begin{array}{l}-0.0717 \\
(0.0052)\end{array}$ \\
\hline $\ln ($ female net wage $)$ & $\begin{array}{l}-0.0031 \\
(0.0009)\end{array}$ & $\begin{array}{l}-0.0717 \\
(0.0052)\end{array}$ & $\begin{array}{c}0.1239 \\
(0.0069)\end{array}$ \\
\hline $\ln (\mathrm{y} / \mathrm{P})$ & $\begin{array}{l}-0.0090 \\
(0.0006)\end{array}$ & $\begin{array}{l}-0.1687 \\
(0.0067)\end{array}$ & $\begin{array}{l}-0.1694 \\
(0.0050)\end{array}$ \\
\hline Inverse Mills Ratio (gasoline) & $\begin{array}{l}-0.0168 \\
(0.0024)\end{array}$ & $\begin{array}{c}0.1820 \\
(0.0269)\end{array}$ & $\begin{array}{c}0.1653 \\
(0.0212)\end{array}$ \\
\hline Male Age & $\begin{array}{c}0.0003 \\
(0.0002)\end{array}$ & $\begin{array}{l}-0.0004 \\
(0.0016)\end{array}$ & $\begin{array}{c}0.0006 \\
(0.0011)\end{array}$ \\
\hline Male Age Squared & $\begin{array}{l}-0.000003 \\
(0.000002)\end{array}$ & $\begin{array}{c}0.000007 \\
(0.000020)\end{array}$ & $\begin{array}{l}-0.000004 \\
(0.000014)\end{array}$ \\
\hline Black Male & $\begin{array}{l}-0.0006 \\
(0.0015)\end{array}$ & $\begin{array}{l}-0.0119 \\
(0.0147)\end{array}$ & $\begin{array}{l}-0.0091 \\
(0.0127)\end{array}$ \\
\hline Asian Male & $\begin{array}{l}-0.0011 \\
(0.0018)\end{array}$ & $\begin{array}{c}0.0189 \\
(0.0149)\end{array}$ & $\begin{array}{c}0.0012 \\
(0.0146)\end{array}$ \\
\hline Other Race Male & $\begin{array}{c}0.0002 \\
(0.0014)\end{array}$ & $\begin{array}{l}-0.0243 \\
(0.0110)\end{array}$ & $\begin{array}{c}0.0087 \\
(0.0100)\end{array}$ \\
\hline Male High School Degree & $\begin{array}{l}-0.0020 \\
(0.0010)\end{array}$ & $\begin{array}{c}0.0132 \\
(0.0064)\end{array}$ & $\begin{array}{c}0.0035 \\
(0.0048)\end{array}$ \\
\hline Male More than High School Degree & $\begin{array}{l}-0.0022 \\
(0.0011)\end{array}$ & $\begin{array}{c}0.0192 \\
(0.0076)\end{array}$ & $\begin{array}{c}0.0067 \\
(0.0052)\end{array}$ \\
\hline Female Age & $\begin{array}{c}0.0005 \\
(0.0002)\end{array}$ & $\begin{array}{c}0.0007 \\
(0.0012)\end{array}$ & $\begin{array}{l}-0.0031 \\
(0.0013)\end{array}$ \\
\hline Female Age Squared & $\begin{array}{l}-0.000005 \\
(0.000002)\end{array}$ & $\begin{array}{l}-0.000006 \\
(0.000016)\end{array}$ & $\begin{array}{c}0.000042 \\
(0.000016)\end{array}$ \\
\hline Black Female & $\begin{array}{c}0.0002 \\
(0.0016)\end{array}$ & $\begin{array}{c}-0.0090 \\
(0.0149)\end{array}$ & $\begin{array}{c}-0.0096 \\
(0.0132)\end{array}$ \\
\hline Asian Female & $\begin{array}{c}0.0016 \\
(0.0021)\end{array}$ & $\begin{array}{c}0.0037 \\
(0.0237)\end{array}$ & $\begin{array}{l}-0.0218 \\
(0.0110)\end{array}$ \\
\hline Other Race Female & $\begin{array}{l}-0.0019 \\
(0.0013)\end{array}$ & $\begin{array}{c}0.0235 \\
(0.0103)\end{array}$ & $\begin{array}{l}-0.0124 \\
(0.0099)\end{array}$ \\
\hline Female High School Degree & $\begin{array}{c}0.0004 \\
(0.0009)\end{array}$ & $\begin{array}{l}-0.0044 \\
(0.0062)\end{array}$ & $\begin{array}{c}0.0103 \\
(0.0060)\end{array}$ \\
\hline Female more than High School Degree & $\begin{array}{c}0.0004 \\
(0.0010)\end{array}$ & $\begin{array}{l}-0.0032 \\
(0.0067)\end{array}$ & $\begin{array}{c}0.0205 \\
(0.0067)\end{array}$ \\
\hline Number of Children & $\begin{array}{c}0.0004 \\
(0.0002)\end{array}$ & $\begin{array}{l}-0.0019 \\
(0.0013)\end{array}$ & $\begin{array}{c}0.0075 \\
(0.0010)\end{array}$ \\
\hline Constant & $\begin{array}{c}0.0904 \\
(0.0054)\end{array}$ & $\begin{array}{c}1.3480 \\
(0.0565)\end{array}$ & $\begin{array}{c}1.4282 \\
(0.0444)\end{array}$ \\
\hline Observations & 7162 & 7162 & 7162 \\
\hline
\end{tabular}

* These are 3SLS regressions with $\ln ($ mean net wage by occupation, by state) instruments for $\ln ($ net wage) and $\ln (\mathrm{y} / \mathrm{P})$ calculated using the price index based on mean expenditure shares as instruments for $\ln (\mathrm{y} / \mathrm{P})$ calculated using individualspecific shares. All regressions include state and month dummy variables. Bootstrapped standard errors are in parentheses. 
Table 4: One-Adult Elasticities

Compensated Price Elasticities

\begin{tabular}{|c|c|c|c|c|c|c|}
\hline & $\mathrm{Ga}$ & & & & Other & Price \\
\hline \multirow[t]{2}{*}{ Gasoline } & \multicolumn{2}{|c|}{-0.750} & \multicolumn{2}{|c|}{0.180} & \multicolumn{2}{|c|}{0.586} \\
\hline & $(-1.095$ & $-0.457)$ & $(0.006$ & $0.355)$ & $(0.255$ & $0.935)$ \\
\hline \multirow[t]{2}{*}{ Labor } & \multicolumn{2}{|c|}{-0.009} & \multicolumn{2}{|c|}{0.353} & \multicolumn{2}{|c|}{-0.296} \\
\hline & $(-0.017$ & $-0.001)$ & $(0.261$ & $0.459)$ & $(-0.384$ & $-0.217)$ \\
\hline \multirow[t]{2}{*}{ Other Good } & \multicolumn{2}{|c|}{0.0163} & \multicolumn{2}{|c|}{0.203} & \multicolumn{2}{|c|}{-0.209} \\
\hline & $(0.008$ & $0.028)$ & $(0.115$ & $0.229)$ & $(-0.242$ & $-0.135)$ \\
\hline \multicolumn{7}{|c|}{ Uncompensated Price Elasticities } \\
\hline & \multicolumn{2}{|c|}{ Gas Price } & \multicolumn{2}{|c|}{ Wage } & \multicolumn{2}{|c|}{ Other Good Price } \\
\hline \multirow[t]{2}{*}{ Gasoline } & \multicolumn{2}{|c|}{-0.771} & \multicolumn{2}{|c|}{0.305} & \multicolumn{2}{|c|}{0.455} \\
\hline & $(-1.088$ & $-0.479)$ & $(0.131$ & $0.474)$ & $(0.084$ & 1.094) \\
\hline \multirow[t]{2}{*}{ Labor } & \multicolumn{2}{|c|}{0.003} & \multicolumn{2}{|c|}{0.040} & \multicolumn{2}{|c|}{0.024} \\
\hline & $(-0.005$ & $0.011)$ & $(-0.066$ & $0.168)$ & $(-0.074$ & $0.128)$ \\
\hline \multirow[t]{2}{*}{ Other Good } & \multicolumn{2}{|c|}{-0.005} & \multicolumn{2}{|c|}{0.621} & \multicolumn{2}{|c|}{-1.009} \\
\hline & $(-0.014$ & $0.005)$ & $(0.356$ & $0.665)$ & $(-1.075$ & $-0.947)$ \\
\hline
\end{tabular}

Bias-corrected 95\% confidence intervals are in parentheses, based on 1500 replications of a nonparametric clustered bootstrap. 
Table 5: Two-Adult Elasticities

\begin{tabular}{|c|c|c|c|c|c|c|c|c|}
\hline \multicolumn{9}{|c|}{ Compensated Price Elasticities } \\
\hline & \multicolumn{2}{|c|}{ Gas Price } & \multicolumn{2}{|c|}{ Male Wage } & \multicolumn{2}{|c|}{ Female Wage } & \multicolumn{2}{|c|}{ Other Good Price } \\
\hline \multirow[t]{2}{*}{ Gasoline } & \multicolumn{2}{|c|}{-0.269} & \multicolumn{2}{|c|}{-0.123} & \multicolumn{2}{|c|}{0.042} & \multicolumn{2}{|c|}{0.354} \\
\hline & $(-0.538$ & $-0.011)$ & $(-0.269$ & $0.003)$ & $(-0.051$ & $0.140)$ & $(0.061$ & $0.639)$ \\
\hline Male & \multicolumn{2}{|c|}{0.007} & \multicolumn{2}{|c|}{0.187} & \multicolumn{2}{|c|}{0.012} & \multicolumn{2}{|c|}{-0.181} \\
\hline Labor & $(0.000$ & $0.015)$ & $(0.105$ & $0.272)$ & $(-0.018$ & $0.042)$ & $(-0.256$ & $-0.096)$ \\
\hline Female & \multicolumn{2}{|c|}{-0.005} & \multicolumn{2}{|c|}{0.028} & \multicolumn{2}{|c|}{0.337} & \multicolumn{2}{|c|}{-0.321} \\
\hline Labor & $(-0.016$ & $0.005)$ & $(-0.030$ & $0.087)$ & $(0.252$ & $0.427)$ & $(-0.415$ & $-0.241)$ \\
\hline Other & \multicolumn{2}{|c|}{0.012} & \multicolumn{2}{|c|}{0.102} & \multicolumn{2}{|c|}{0.095} & \multicolumn{2}{|c|}{-0.201} \\
\hline Good & $(0.002$ & $0.021)$ & $(0.048$ & $0.141)$ & $(0.070$ & $0.123)$ & $(-0.255$ & $-0.134)$ \\
\hline
\end{tabular}

\begin{tabular}{|c|c|c|c|c|c|c|c|c|}
\hline \multicolumn{9}{|c|}{ Uncompensated Price Elasticities } \\
\hline & \multicolumn{2}{|c|}{ Gas Price } & \multicolumn{2}{|c|}{ Male Wage } & \multicolumn{2}{|c|}{ Female Wage } & \multicolumn{2}{|c|}{ Other Good Price } \\
\hline \multirow[t]{2}{*}{ Gasoline } & \multicolumn{2}{|c|}{-0.283} & \multicolumn{2}{|c|}{0.011} & \multicolumn{2}{|c|}{0.110} & \multicolumn{2}{|c|}{0.178} \\
\hline & $(-0.540$ & $-0.021)$ & $(-0.133$ & $0.134)$ & $(0.020$ & $0.213)$ & $(-0.285$ & $0.646)$ \\
\hline Male & \multicolumn{2}{|c|}{0.013} & \multicolumn{2}{|c|}{0.062} & \multicolumn{2}{|c|}{-0.049} & \multicolumn{2}{|c|}{-0.045} \\
\hline Labor & $(0.006$ & $0.022)$ & $(-0.019$ & $0.152)$ & $(-0.080$ & $-0.019)$ & $(-0.126$ & $0.043)$ \\
\hline Female & \multicolumn{2}{|c|}{0.002} & \multicolumn{2}{|c|}{-0.113} & \multicolumn{2}{|c|}{0.242} & \multicolumn{2}{|c|}{-0.165} \\
\hline Labor & $(-0.008$ & $0.013)$ & $(-0.174$ & $-0.055)$ & $(0.158$ & $0.329)$ & $(-0.252$ & $-0.076)$ \\
\hline Other & \multicolumn{2}{|c|}{-0.016} & \multicolumn{2}{|c|}{0.548} & \multicolumn{2}{|c|}{0.328} & \multicolumn{2}{|c|}{-1.090} \\
\hline Good & $(-0.026$ & $-0.007)$ & $(0.314$ & $0.588)$ & $(0.295$ & $0.362)$ & $(-1.154$ & $-1.003)$ \\
\hline
\end{tabular}

Bias-corrected $95 \%$ confidence intervals are in parentheses, based on 1500 replications of a nonparametric clustered bootstrap. 
Table 6: Estimated Optimal Tax Rates

(One-Adult Households Only)

\begin{tabular}{|c|c|c|c|c|c|}
\hline & MED & \multicolumn{2}{|c|}{$\mathrm{MCPF}$} & \multicolumn{2}{|c|}{ Optimal Tax Rate } \\
\hline $\begin{array}{c}\text { First-best } \\
\text { (partial equilibrium) }\end{array}$ & $\$ 0.77$ & \multicolumn{2}{|c|}{1} & \multicolumn{2}{|c|}{$\$ 0.77$} \\
\hline Second-best & $\$ 0.77$ & \multicolumn{2}{|c|}{1.01} & \multicolumn{2}{|c|}{$\$ 0.76$} \\
\hline (separable \& homothetic) & & $(0.99$ & $1.03)$ & $(\$ 0.74$ & $\$ 0.78)$ \\
\hline Second-best & $\$ 0.77$ & \multicolumn{2}{|c|}{1.01} & \multicolumn{2}{|c|}{$\$ 0.87$} \\
\hline (separable, nonhomothetic) & & $(0.99$ & $1.03)$ & $(\$ 0.83$ & $\$ 0.92)$ \\
\hline Second-best & $\$ 0.77$ & \multicolumn{2}{|c|}{1.01} & \multicolumn{2}{|c|}{$\$ 0.82$} \\
\hline (nonseparable, nonhomothetic) & & $(0.99$ & $1.03)$ & $(\$ 0.73$ & $\$ 0.95)$ \\
\hline
\end{tabular}

(Two-Adult Households Only)

\begin{tabular}{|c|c|c|c|c|c|}
\hline & MED & \multicolumn{2}{|c|}{ MCPF } & \multicolumn{2}{|c|}{ Optimal Tax Rate } \\
\hline $\begin{array}{c}\text { First-best } \\
\text { (partial equilibrium) }\end{array}$ & $\$ 0.77$ & \multicolumn{2}{|c|}{1} & \multicolumn{2}{|c|}{$\$ 0.77$} \\
\hline Second-best & $\$ 0.77$ & \multicolumn{2}{|c|}{1.03} & \multicolumn{2}{|c|}{$\$ 0.75$} \\
\hline (separable \& homothetic) & & $(1.00$ & $1.05)$ & $(\$ 0.73$ & $\$ 0.77)$ \\
\hline Second-best & $\$ 0.77$ & \multicolumn{2}{|c|}{1.03} & \multicolumn{2}{|c|}{$\$ 1.01$} \\
\hline (separable, nonhomothetic) & & $(1.00$ & $1.05)$ & $(\$ 0.66$ & $\$ 3.30)$ \\
\hline Second-best & $\$ 0.77$ & \multicolumn{2}{|c|}{1.03} & \multicolumn{2}{|c|}{$\$ 1.30$} \\
\hline (nonseparable, nonhomothetic) & & $(1.00$ & $1.05)$ & $(\$ 0.82$ & $\$ 5.34)$ \\
\hline
\end{tabular}

(All Households)

\begin{tabular}{|c|c|c|c|c|c|}
\hline & MED & \multicolumn{2}{|c|}{ MCPF } & \multicolumn{2}{|c|}{ Optimal Tax Rate } \\
\hline $\begin{array}{c}\text { First-best } \\
\text { (partial equilibrium) }\end{array}$ & $\$ 0.77$ & \multicolumn{2}{|c|}{1} & \multicolumn{2}{|c|}{$\$ 0.77$} \\
\hline Second-best & $\$ 0.77$ & \multicolumn{2}{|c|}{1.02} & \multicolumn{2}{|c|}{$\$ 0.75$} \\
\hline (separable \& homothetic) & & $(1.00$ & $1.04)$ & $(\$ 0.74$ & $\$ 0.77)$ \\
\hline Second-best & $\$ 0.77$ & \multicolumn{2}{|c|}{1.02} & \multicolumn{2}{|c|}{$\$ 0.93$} \\
\hline (separable, nonhomothetic) & & $(1.00$ & $1.04)$ & $(\$ 0.84$ & $\$ 1.18)$ \\
\hline Second-best & $\$ 0.77$ & \multicolumn{2}{|c|}{1.02} & \multicolumn{2}{|c|}{$\$ 1.04$} \\
\hline (nonseparable, nonhomothetic) & & $(1.00$ & 1.04) & $(\$ 0.87$ & $\$ 1.48)$ \\
\hline
\end{tabular}

All monetary values are in 1997 dollars. Bias-corrected 95\% confidence intervals are in parentheses, based on 1500 replications of a nonparametric clustered bootstrap. Marginal external damage (MED) includes congestion and accident damages as well as environmental damages. MED estimates are taken from Parry and Small (2002) and deflated from 2000 to 1997 dollars. 


\section{Appendix 1: Derivations and Elasticity Formulas}

\section{Derivation of Equation (14)}

It is useful first to find expressions for how $\tau_{L}$ and $T$ change for a change in $\tau_{Y}$. Taking a total derivative of (9) with respect to $\tau_{Y}$ and substituting in (5) and (6) yield

$$
\frac{d \tau_{L}^{h i}}{d \tau_{Y}}=\frac{w^{h i}}{1-\tau_{Y}} \text { and } \frac{d \mathrm{~T}^{h}}{d \tau_{Y}}=\frac{I^{h}}{1-\tau_{Y}} .
$$

To derive an expression for the aggregate change in utility from a change in $\tau_{Y}$, take the total derivative of utility (1) with respect to $\tau_{Y}$, sum over households, substitute in the firstorder conditions (10) and a total derivative of the consumer budget constraint (3) with respect to $\tau_{Y}$, and rearrange terms. Note that (14) is a "non-environmental" definition of the MCPF, so we ignore the externality term in (1). This gives

$$
\sum_{h} \frac{1}{\lambda^{h}} \frac{d U^{h}}{d \tau_{Y}}=-\sum_{h}\left[\frac{d T^{h}}{d \tau_{Y}}+\sum_{i} L^{h i} \frac{d \tau_{L}^{h i}}{d \tau_{Y}}\right]
$$

To derive an expression for the change in government revenue from a change in $\tau_{Y}$, take the total derivative of the left-hand side of the government budget constraint (8) with respect to $\tau_{Y}$ and rearrange terms. Because (14) is a "non-environmental" MCPF, we ignore the revenue from the tax on the polluting good. This gives

$$
d \sum_{h}\left[\sum_{i} \tau_{L}^{h i} L^{h i}+T^{h}\right] / d \tau_{Y}=\sum_{h}\left[\frac{d T^{h}}{d \tau_{Y}}+\sum_{i}\left(L^{h i} \frac{d \tau_{L}^{h i}}{d \tau_{Y}}+\tau_{L}^{h i} \frac{\partial l^{h i}}{\partial I^{h}} \frac{d T^{h}}{d \tau_{Y}}+\sum_{j} \tau_{L}^{h i} \frac{\partial l^{h i}}{\partial w^{h j}} \frac{d \tau_{L}^{h j}}{d \tau_{Y}}\right)\right] .
$$

Dividing (A2) by (A3) and then substituting in (A1) and (3) give (14).

\section{Derivation of Equation (15)}

The total derivative $\frac{d l^{i}}{d \tau_{D}}$ depends on how the income tax adjusts to hold government

revenue constant. Taking a total derivative of the government budget constraint (8), substituting in (A1) and the equation for the MCPF (14) and rearranging yield

$$
\frac{d \tau_{Y}}{d \tau_{D}}=-\left(1-\tau_{Y}\right) \eta \sum_{h}\left[D^{h}+\tau_{D} \frac{d D^{h}}{d \tau_{D}}-\sum_{i} \tau_{L}^{h i} \frac{\partial l^{h i}}{\partial p_{D}^{h}}\right] / \sum_{h} Y^{h} .
$$


Starting with the last term in (12) and substituting in $\frac{d l^{h i}}{d \tau_{D}}=\frac{\partial l^{h i}}{\partial p_{D}^{h}}-\frac{\partial l^{h i}}{\partial w^{h i}} \frac{d \tau_{L}^{h i}}{d \tau_{Y}} \frac{d \tau_{Y}}{d \tau_{D}}-\frac{\partial l^{h i}}{\partial I^{h}} \frac{d T^{h}}{d \tau_{Y}} \frac{d \tau_{Y}}{d \tau_{D}}$, (A1) and (A4) yields equation (15).

Demand Derivatives in Terms of Estimated Parameters

The demand system used in this paper does not directly yield estimates of derivatives or elasticities of demand; instead, these derivatives and elasticities are functions of the estimated parameters. Taking a derivative of the AIDS budget share equation (18) with respect to $p_{i}^{h}$ gives

(A5) $\frac{\partial s_{j}^{h}}{\partial p_{i}^{h}}=\frac{\gamma_{j i}}{p_{i}^{h}} \alpha_{j}-\beta_{j} \frac{\partial\left(\log P^{h}\right)}{\partial p_{i}^{h}}$.

Taking a similar derivative of the price index (22) yields

$$
\frac{\partial\left(\log P^{h}\right)}{\partial p_{i}^{h}}=\frac{s_{i}^{h}}{p_{i}^{h}}+\sum_{k} \log \left(p_{k}^{h} / \bar{p}_{k}\right) \frac{\partial s_{k}^{h}}{\partial p_{i}^{h}}
$$

Solving (A5) and (A6) for $\frac{\partial s_{j}^{h}}{\partial p_{i}^{h}}$ and then converting the share into a quantity yields an expression for the uncompensated derivative of demand for good $i$ with respect to the price of good $j$ (where $j$ is any good except leisure):

$$
\frac{\partial q_{j}^{h}}{\partial p_{i}^{h}}=\frac{y^{h}}{p_{i}^{h} p_{j}^{h}}\left[\gamma_{j i}-\beta_{j} \frac{s_{i}^{h}+\sum_{k} \gamma_{k i} \log \left(p_{k}^{h} / \bar{p}_{k}\right)}{1+\sum_{k} \beta_{k} \log \left(p_{k}^{h} / \bar{p}_{k}\right)}\right]+\frac{q_{i}^{h} q_{j}^{h}}{y^{h}}-\frac{q_{j}^{h}}{p_{i}^{h}} d_{i j},
$$

where $q_{j}^{h}$ is the quantity of good $j$ consumed and $d_{i j}$ is the Kronecker delta, equal to 1 if $i=j$ and zero otherwise.

A similar process for a change in income gives

$$
\frac{\partial q_{j}^{h}}{\partial y^{h}}=\frac{1}{p_{j}^{h}}\left[\frac{\beta_{j}}{1+\sum_{k} \beta_{k} \log \left(p_{k}^{h} / \bar{p}_{k}\right)}\right]+\frac{q_{j}^{h}}{y^{h}} .
$$

It is then straightforward to use the Slutsky equation to obtain the compensated derivative of demand for good $i$ with respect to the price of good $j$, which is given by 


$$
\frac{\partial q_{j C}^{h}}{\partial p_{i}^{h}}=\frac{y^{h}}{p_{i}^{h} p_{j}^{h}}\left[\gamma_{j i}+\beta_{j} \frac{\sum_{k} \gamma_{k i} \log \left(p_{k}^{h} / \bar{p}_{k}\right)}{1+\sum_{k} \beta_{k} \log \left(p_{k}^{h} / \bar{p}_{k}\right)}\right]+\frac{q_{i}^{h} q_{j}^{h}}{y^{h}}-\frac{q_{j}^{h}}{p_{i}^{h}} d_{i j},
$$

where the subscript $\mathrm{C}$ denotes a compensated derivative.

\section{Correcting Derivatives for Corner Solutions}

The expressions in (A7-A9) are valid for a household that is at an interior solution, but not for those at corner solutions (i.e., those households who don't consume gasoline, or where one or both adults do not work). The parameter estimates should still be valid for these households (because of the corrections for selectivity described in Appendix 2), but the expressions for derivatives in terms of the estimated parameters will differ. We follow the standard "virtual price" approach, recognizing that a household at a corner will have a shadow price for the good that it is not consuming (or, in the case of leisure, that it is consuming its entire endowment of) that differs from the true price, as a result of the constraint imposed by the corner. This implies that if a household is constrained in its consumption of good $k$ then

$$
\frac{\partial \hat{q}_{j C}^{h}}{\partial p_{i}^{h}}=\frac{\partial q_{j C}^{h}}{\partial p_{i}^{h}}-\frac{\partial q_{j C}^{h}}{\partial p_{k}^{h}}\left(\frac{\partial q_{k C}^{h}}{\partial p_{i}^{h}} / \frac{\partial q_{k C}^{h}}{\partial p_{k}^{h}}\right)
$$

where the "hat" denotes the derivative after correcting for the corner solution. Similarly,

$$
\text { (A11) } \frac{\partial \hat{q}_{j C}^{h}}{\partial y^{h}}=\frac{\partial q_{j C}^{h}}{\partial y^{h}}-\frac{\partial q_{j C}^{h}}{\partial p_{k}^{h}}\left(\frac{\partial q_{k C}^{h}}{\partial y^{h}} / \frac{\partial q_{k C}^{h}}{\partial p_{k}^{h}}\right) \text {. }
$$

Because consumption of good $k$ is constrained, derivatives of demand for good $k$, or with respect to the price of good $k$ will equal zero. ${ }^{27}$ It is then straightforward to apply the Slutsky equation to obtain uncompensated derivatives (recognizing that the income effect for leisure will differ, because the household starts with an endowment of leisure).

\section{Aggregating Elasticities}

We report aggregate elasticities in Tables 4 and 5 to clarify what is driving the optimal tax

\footnotetext{
${ }^{27}$ If a household is at a corner solution for two goods, then this approach can be applied sequentially for the two goods.
} 
results. Thus, it is necessary to aggregate individual household demand derivatives to obtain aggregate elasticities. In doing this, we calculate the elasticity for a case in which each household faces the same absolute change in price. ${ }^{28}$ This implies that the aggregate demand elasticity is given by

(A12) $\varepsilon_{j i}=\bar{p}_{i} \sum_{h} \frac{\partial q_{j}^{h}}{\partial p_{i}^{h}} / \sum_{h} q_{j}^{h}$,

where

(A13) $\bar{p}_{i}=\sum_{h} p_{i}^{h} q_{i}^{h} / \sum_{h} q_{i}^{h}$

(note that this is the same average price that is used in computing the price index in (22). The equations for aggregate labor supply elasticities differ slightly, in that the quantities in (A12) and (A13) are replaced with the amount of labor supplied.

${ }^{28}$ The reported elasticities are obviously somewhat sensitive to this assumption-because households initially face different prices, an equal-percentage change in price would give a slightly different result-and it is not entirely clear which assumption would be more appropriate. Fortunately, this has no effect on the optimal tax results, because the optimal tax formula in (16) is calculated using individual household demand derivatives, not aggregates. 
Appendix 2: Correcting for Selectivity Bias

This section explains corrections made for potential selection into work and into gasoline consumption. Results for the estimation discussed here are available from the authors by request.

1. The work decision

Since we do not observe wages for individuals who are not working, we follow Heckman (1979) to correct for the associated selectivity bias and obtain estimated selectivity-corrected net wages for workers and nonworkers. First we specify a probit of the choice to work or not work. We obtain the predicted inverse Mills ratio for each individual from the probit to include in an equation that estimates net wages. Rather than estimate the selection model in two separate stages, we estimate the probit and net wage regression jointly using full information maximum likelihood.

We estimate selection models separately for the one-adult and two-adult households, and within those samples, separately for men and for women. The one-adult probits include age, age squared, education, race, marital status, number of children, region, the log of gas price, the log of other good price, and state-specific quarterly unemployment rates. ${ }^{29}$ The two-adult probits contain the variables in the one-adult probits plus partner's earnings and partner's demographic information.

Because of the linear approximation to the price index (22), wages affect the price derivatives of demand even for non-workers (though this effect is minimal), and thus we need to predict wages for non-workers as well as for workers. Because occupation is an important determinant of net wage but is observed only for workers, we run two selection models for each subsample, one to estimate workers' net wages and the other to estimate nonworkers' net wages. Within each subsample (where one such subsample, for example, is composed of women from one-adult households) both the selection models use the same set of observations of workers and nonworkers and identical probits. We use different wage regressions, however, to estimate net wages for workers and for nonworkers. To estimate net wages for nonworkers we specify a wage equation that includes education, age, age squared, race, marital status, region, and the inverse

\footnotetext{
${ }^{29}$ Unemployment rates are gathered from the Bureau of Labor Statistics at www.bls.gov.
} 
Mills ratio from the probits. To estimate net wages for workers, we include those same variables plus occupation indicators. Since net wages are distributed log normal, we define the dependent variable as the log of net wage. We calculate predicted net wages for workers to include in demand system estimation.

In principle, the Heckman selection model is identified even when the variables in the probit and the wage regression are the same. In that case, the model is identified by its functional form and the normality assumption. Note, however, that the probits include number of children, the log of gas price, the log of the other good price, state-specific quarterly unemployment rates, and, in the case of two-adult households, partner's earnings; the wage equations do not. Number of children affects the fixed cost of working and thus the participation decision. But we do not expect number of children to affect the wage, since we control for age, race, and gender; number of children is a standard exclusion restriction in the labor supply literature. Our demand system allows gas and other good prices to affect the continuous demand for leisure and thus it is reasonable to assume that they also affect the discrete work choice. While high price regions may also be high wage regions, there is no reason to postulate that an individual facing a high gas price or other good price will have a higher wage, since we control for region in our wage equation. Unemployment rates proxy for job availability in a state and thus affect the likelihood of working, but it is not clear why they would affect wages. Partner's earnings proxy for an individual's nonwage income, but should not directly affect an individual's wage; this is another standard exclusion restriction.

\section{The gasoline decision}

Since some households have zero expenditure on gasoline, another selection bias may arise. Heien and Wessels (1990) proposes a procedure for dealing with households that consume none of a good. They estimate a probit of the dichotomous choice to consume or not consume a particular good and obtain inverse Mills ratios defined in Heckman (1979). They include these inverse Mills ratios in all equations of the demand system. 
Shonkwiler and Yen (1999), however, finds that especially in the case of a large number of censored observations, the Heien and Wessels procedure is biased. They recommend an alternative unbiased approach that still allows for the demand system to be estimated over all households. However, we cannot use the approach suggested by Shonkwiler and Yen, because we need to use instrumental variables to estimate our system, and their approach would yield inconsistent estimates if used along with instrumental variables.

Like Heien and Wessels (1990), we use the results of the probit on the dichotomous choice to consume or not consume gasoline to calculate an inverse Mills ratio for each household. We run separate probits for one-adult and two-adult households. Each probit includes the log of total goods expenditures, age, age squared, race, marital status, the number of children, region, an indicator for whether the household owns its house, and the logs of gas price and other good price. Demographic variables for both adults are included in the two-adult probit. Home ownership acts as a proxy for wealth and access to credit and thus increases the likelihood of owning an automobile and the likelihood of consuming gasoline (see West, 2004). We do not expect it to affect the continuous choice of gasoline and we therefore use it as an exclusion restriction.

Also like Heien and Wessels (1990), we include the inverse Mills ratio from the discrete gas choice in all equations of our demand system. We, however, estimate the system on only households that consume gasoline in which all adults work, whereas Heien and Wessels estimated the system for all households, not just those that consume positive amounts of all goods. In their case, it was particularly important to keep all households in the system estimation, because they estimated a demand system defined over some goods that the majority of households did not consume. We lose relatively few households that consume no gasoline; in the one-adult sample, 510 households buy no gasoline; in the two-adult sample 56 households buy none. And, by excluding from the estimation households that do not consume gasoline, we avoid the bias noted by Shonkwiler and Yen. In this sense our correction is exactly analogous to that in Heckman (1979), in which the second stage regression is estimated only over uncensored households. 